\title{
Optimal sizing and sitting of electric vehicle charging station by using Archimedes optimization algorithm technique
}

\author{
Mohamed Abdelhamed Zaki ${ }^{1}$, Tarek Mahmoud ${ }^{2}$, Mohamed Atia ${ }^{3}$, El Said Abd El Aziz Osman ${ }^{4}$ \\ ${ }^{1,3}$ Department of Electrical Power and Machines Engineering, the Higher Institute of Engineering, Elshorouk City, Egypt \\ ${ }^{2,4}$ Department of Electrical Engineering, Al-Azhar University, Cairo, Egypt
}

\section{Article Info \\ Article history: \\ Received May 6, 2021 \\ Revised Sep 17, 2021 \\ Accepted Sep 24, 2021}

\section{Keywords:}

Electric vehicles

Optimal sizing and sitting of EV-CSs

Particle swarm optimization

Cuckoo search algorithm

Archimedes optimization algorithm

\begin{abstract}
Increasing penetration of electric vehicle (EV) load into the electricity sector will result in generation imbalance, an increase in real power loss, a low voltage profile and consequently a decrease in the margin of stability of voltage. It is necessary for the coordination of charging stations (CSs) for EV at the relevant locations to minimize the effect of increased EV load penetration in radial systems. In this paper, a new optimization method named Archimedes optimization algorithm (AOA) is proposed; it determined the optimal location and size for EV-CS for reducing power losses and improved voltage profile. In this work we used the photovoltaic (PV) renewable source as a main feeder for the CSs. Many of Artificial Intelligence technique are applied to determine the optimal sizing and sitting of EV-CSs considering the objective of minimization of real power loss. IEEE 33-bus testing network conducts simulation tests. The results highlighted the need to refine the EV-CS allocation to improve the performance. The ability to solve complex, non-linear objective optimization issues using AOA and to compare the results with other algorithms, namely particle swarm optimization (PSO), cuckoo search algorithm (CSA), shows its effectiveness in minimizing the power loss as required.
\end{abstract}

This is an open access article under the $\underline{C C B Y-S A}$ license.

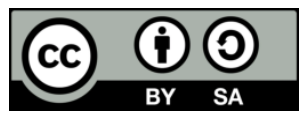

Corresponding Author:

Mohamed Abdelhamed Zaki

Department of Electrical Power and Machines Engineering

The Higher Institute of Engineering

Elshorouk City, Cairo, Egypt

Email:m.zaky@sha.edu.eg

\section{INTRODUCTION}

Today, the world's demand for fossil fuels is increasing rapidly in both the transport and power generation sectors. Not only does the use of these tools contribute to high prices, but also to greenhouse gas emissions and environmental pollution. [1]. According to studies presented in [2], Production will rise by $54 \%$ in the transport industry by 2035 , which will increase prices and air pollution by significant demand. Therefore, many nations are seeking to replace green vehicles instead of internal combustion cars [3]. Electric vehicles (EVs) have shown additional benefits compared with their fossil fuel vehiclecounterparts. They produce fewer emissions even when considering their whole process of energy production, independently of their energy source [4]. Electric vehicle (EV) is an up-and-coming solution for the problem of transportation and pollution [5]. The first technology introduced will take place via vehicle-to-grid in 1977 [6]. This promising framework has been first used by the provision of a revenue and expenditure model for regulatory and auxiliary services [7]. 
Penetrations of electrical vehicles (EVs) in the grid face challenges including thermal limit breaches in certain sensitive network buses of transmission lines because of overload or voltage drop and demand uncertainty [8], [9]. The most popular vehicles in the parking mode are almost $95 \%$ of the day, according to previous studies. As a consequence, can be used this capacity for frequency and voltage regulation through V2G [10]. Vehicle participation in V2G generates money for owners of cars. It can also be used to minimize network challenges by using EV and PHEV charging station capabilities [11], [12]. Vehicles will refill batteries at these stations and sell excess stored energy to grid and profit from it. In this situation, it is possible to handle the charging and discharging of vehicles using various approaches, such as adjusting energy tariffs at different time slots.

Renewable sources have been widely regarded in recent years as an alternative to fossil-fuel power plants. Since these tools can be mounted near the load, losses and voltage fluctuations can be minimized [13], Because of the random nature of their output, the widespread penetration of these resources into the grid may create challenges. Consequently, high-capacity energy storage devices can be used to sustain the network. In this sense, charging stations can be integrated into the network as ESS via V2G. Charging stations store excess power generated by RES and injects it into the electricity grid in due course, distributing the energy and reducing the burden on the distribution network. Emission rates are minimized in a smart grid with an optimum mix of RES and PHEV charging stations and many technological and economic problems can be solved effectively [14].

Literature reviews many researchers have investigated the design and operation of EV CSs and PV renewable source on the distribution systems and little researcher used the Archimedes optimization algorithm (AOA). Li et al. [15], the AOA to choose the optimum location and capacity of DG and used the power losses objective and compare between the results by using AOA, IGA and particle swarm optimization (PSO). Ali et al. [16] presented an objective optimization approach is formulated to optimally size multiple DGs and SOPs placements via AOA and NR from the planning and operational viewpoints, Case studies are conducted on the real distribution networks, including the 59-node distribution network in Cairo and the 135node distribution network in Brazil, to step on the effectiveness of SOPs insertion in enhancing DGs penetration. Various EV-PV charger architectures were tested and analyses. Mouli et al. [17], the charger of EV-PV was presented with two optimal designs. Goli and Shireen [18], design of smart charging station was implemented in which the charging of the PHEVs was controlled to minimize the effect of charging during the peak load period on the grid. The PHEVs were paid in that scheme via the PV of grid-connected system and/or the utility a special controller has been developed to allow effective energy transfer while at the same time reducing the conversion stage between source and load. [19]. The system consists of modules designed to enhance flexibility and encourage development. In an unregulated charge method, the integration of PV and EVs was studied [20]. In addition, we explored the implementation of intelligent charging and V2G strategies. The paper has shown that the grid strategy vehicles can be used to rub the peaks of the classical load curve using the PV output.

Hafez and Bhattacharya [21] proposed optimum configuration, with regard to renewable energy and diesel generation, for an electric vehicle charge station (EVCS). The goal was that the lifecycle costs were reduced while taking environmental pollution into account. Mouli et al. [22] proposed the option of charging EV on site using an optimized storage power system PV has been investigated. A comparison between these profiles and a comparison between these profiles were carried out to minimize the reliance on grids and to optimize the use of PV power to charge the electricity directly. Khan et al. [23], the proposed rapid delivery network linked EV-CS model. By reducing harmonic current, the proposed model improves the power efficiency. In order to minimize the effect of fast charging on the grid, a PV power system was also developed with a strategy focused on optimum power flow EV-CS. A genetic algorithm was used by optimizing benefit determined by its net current value to maximize the installation and activity of EV fast charging [24]. In order to increase the profitability of the stations and decrease the high grid energy requirements, wind, photovoltaic and storage systems have been connected to EV-CS.

The main contributions of this work are illustrated as follows: 1) discusses the impact of EV-CSs on electric feeder losses by feeding the PV, 2)the main objective of this paper is to detect the optimal allocation of CSs for loss reduction subjected to system constraints, 3) the PSO, Cuckoo search algorithm (CSA), and AOA techniques are used to detect the optimal placement for the CSs, 4) the proposed algorithm is applied to a standard 33-bus radial distribution system, to determine optimum size and location of EV-CS, and 5) the results are analysed and compared.

This paper is organized; section 2 presents the mathematical formulation of the problem. The definition and description of the PSO, CSA, and AOA methods are introduced in section 3. Section 4 presents the procedure used for solving the problem whereas section 5 introduces numerical applications and case studies. The results and discussion are introduced in section 6, whereas section seven concludes the paper. 


\section{PROBLEM FORMULATION}

The problem is formulated as an optimization for general CSs placement considering practical features of CS, the operation, and load restrictions at different rates of the load. The optimization problem is formulated with a non-differentiable objective function. This paper proposes a solution algorithm depends on PSO, CSA and AOA techniques and aims to detect the locations where CSs are to be installed. The algorithm can detect the global optimal solution for sitting the CSs.

\subsection{Objective function}

The aim of this article is to find the best locations and size of charge station by increase the system losses. The problem of optimization is conceived as one purpose function. The calculation of the power loss in the line section connecting buses $i$ and $i+1$ before integrating any charging station formulated as (1) [25]:

$$
P_{\text {Loss }}(i . i+1)=R_{i}\left(\frac{P_{i}^{2}+Q_{i}^{2}}{\left|V_{i}^{2}\right|}\right)
$$

where:

$\mathrm{R}_{\mathrm{i}} \quad$ : the section line resistance, $\Omega$

$\mathrm{P}_{\mathrm{i}}$ : active power of the $\mathrm{i}^{\text {th }}$ bus, $\mathrm{W}$

$\mathrm{Q}_{\mathrm{i}}$ : reactive power of the $\mathrm{i}^{\text {th }}$ bus, VAR

$\mathrm{V}_{\mathrm{i}}$ : voltage of the $\mathrm{i}^{\text {th }}$ bus, $\mathrm{V}$

The total network losses are calculated as (2):

$$
P_{\text {TLoss }}(i . i+1)=\sum_{i=1}^{n} \mathrm{I}_{\mathrm{i}}^{2} \mathrm{R}_{\mathrm{i}}
$$

where $\mathrm{n}$ is the total line sections in the system.

Network losses can be formulated due to the addition of CSs as (3) [25]:

$$
P^{\prime}{ }_{\text {TLoss }}(i . i+1)=\sum_{i=1}^{n} \mathrm{I}_{\mathrm{T}}^{2} \mathrm{R}_{\mathrm{i}}
$$

where $\mathrm{I}_{\mathrm{T}}$ is the current total line section, including the current charging station.

The PV losses to the charge station are represented:

$$
P^{\prime \prime}{ }_{T L o s s}=\sum_{i=1}^{n}\left(\mathrm{I}_{\mathrm{cs}}-\mathrm{I}_{\mathrm{pv}}\right)^{2} \mathrm{R}_{\mathrm{i}}
$$

where $\mathrm{I}_{\mathrm{pv}}$ is photovoltaic current delivered to the CS or the utility.

Substituting (6) it is proposed objective function can be expressed as (5):

$$
\operatorname{Min} . P_{\text {TLoss }}=\sum_{i=1}^{n}\left(I_{i}+I_{c s}-I_{p v}\right)^{2} R_{i}
$$

\subsection{Constraints}

Voltage constraints: maximum and minimum voltages limits at each busbar that is, $\pm 5 \%$ of the nominal value.

$$
0.95 \mathrm{pu} \leq \mathrm{V}_{\mathrm{i}} \leq 1.05 \mathrm{pu}
$$

Line loading constraints: maximum and minimum apparent power limits of each line.

$$
S_{i j \_ \text {min }} \leq S_{i j} \leq S_{i j \_\max }
$$

Charging stations' capacity constraints: maximum and minimum limits of each EV-CS capacity.

$$
\mathrm{CCS}_{\mathrm{k} \_ \text {min }} \leq \mathrm{CCS}_{\mathrm{k}} \leq \mathrm{CCS}_{\mathrm{k} \_ \text {max }}
$$

Active power balance constraints: the total generated active power must equal the demand active power plus the losses.

$$
\mathrm{P}_{\mathrm{i}+1}=\mathrm{P}_{\mathrm{i}}-\mathrm{P}_{\text {loss.i }}-\mathrm{P}_{\mathrm{L} . \mathrm{i}+1}
$$


Reactive power balance constraints: the total generated reactive power must equal the demand reactive power plus the losses.

$$
Q_{i+1}=Q_{i}-Q_{\text {loss.i }}-Q_{L . i+1}
$$

The (9) and (10) can be modelled through the following mathematical relations [25].

$$
\begin{aligned}
& P_{i+1}=P_{i}-P_{\text {loss } . i}-P_{L . i+1}=P_{i}-\frac{R_{i}}{\left|V_{i}^{2}\right|}\left(P_{i}^{2}+\left(Q_{i}+Y_{i}\left|V_{i}^{2}\right|^{2}\right)^{2}\right)-P_{L . i+1} \\
& Q_{i+1}=Q_{i}-Q_{\text {loss.i }}-Q_{L . i+1} \\
& =Q_{i}-\frac{X_{i}}{\left|V_{i}^{2}\right|}\left(P_{i}^{2}+\left(Q_{i}+Y_{i 1}\left|V_{i}^{2}\right|^{2}\right)^{2}\right)-Y_{i 1}\left|V_{i}^{2}\right|-Y_{i 2}\left|V_{i+1}^{2}\right|-Q_{L . i+1} \\
& \left|V_{i+1}^{2}\right|=\left|V_{i}^{2}\right|+\frac{R_{i}^{2}+X_{i}^{2}}{\left|V_{i}^{2}\right|}\left(P_{i}^{2}+Q_{i}^{2}\right)-2\left(R_{i} P_{i}+X_{i} Q_{i}\right)
\end{aligned}
$$

where:

$V_{\min }, V_{\max } \quad:$ minimum and maximum bus voltages,

$C C S_{k} \quad: \quad$ capacity of the $k^{\text {th }} \mathrm{PV}$ charging station,

$C C S_{k_{-} \min } \quad: \quad$ minimum capacity of the $k^{\text {th }} \mathrm{PV}$ charging station,

$C C S_{k_{-} \text {max }} \quad: \quad$ maximum capacity of the $k^{\text {th }} \mathrm{PV}$ charging station,

$S_{i j} \quad:$ apparent power in the line connecting between bus $i$ and bus $j$,

$S_{i j \_ \text {min }}:$ minimum apparent power of the line $i j$,

$S_{i j \_ \text {max }}:$ maximum apparent power of the line $i j$,

$P_{i}, Q_{i} \quad: \quad$ real and reactive power flow out of the $i^{\text {th }}$ bus,

$P_{L . i+1}, Q_{L i+1}:$ load real and reactive power at bus $i+1$,

$R_{i}, X_{i} \quad: \quad$ section line resistance and reactance respectively

\section{RESULTS AND DISCUSSION}

\subsection{Particle swarm optimization algorithm}

To determine EV-CS location and sizing, PSO algorithm [26], [27] is applied to optimize the constrained objective function in (14) for the case study. The number of variables in the optimization problem is 2 . Thus, each particle of swarm searches for optimal result in 2-dimensional search space. Can be represented the particle as:

$$
\text { Particle }_{i}=\left(L_{C S}, P_{C S}\right)
$$

where, $L_{C S}$ is the EV-CS location and $P_{C S}$ is the EV-CS size. The flowchart of optimization technique using PSO shown in Figure1.

\subsection{Cuckoo search algorithm}

Cuckoo search (CS) is an optimization algorithm which invented by Yang and Deb [28].CS is driven by the aggressive parasitism behavior of cuckoo species that lay their eggs with fascinating abilities in the nests of other host birds, such as the selection of newly spawned nests and the removal of host bird eggs that increase the likelihood of hatching their eggs. Eggs are taken care of by the host bird, assuming that the eggs are their own. If a host bird finds foreign eggs in its nest, it either leaves the nest and otherwise builds a new nest or merely throws away the foreign eggs. This method is based on three basic rules [29]. In a randomly selected nest, each cuckoo lays one egg (solution) at a time; the best option (nest) with the best quality eggs will be transported to the next generation. The number of host nests available is set, and the egg laid by a cuckoo is found by the host bird with a probability $\mathrm{p}_{\mathrm{a} \in}[0,1]$ of the host bird will either throw away the alien egg or leave the nest and establish a new nest. A cuckoo egg represents a new solution to define this algorithm for simplicity, while each host bird egg in a nest represents a solution. The goal is to substitute the latest and even better alternatives for the worst solution in the nests. The flowchart of optimization technique using CS shown in Figure2. 


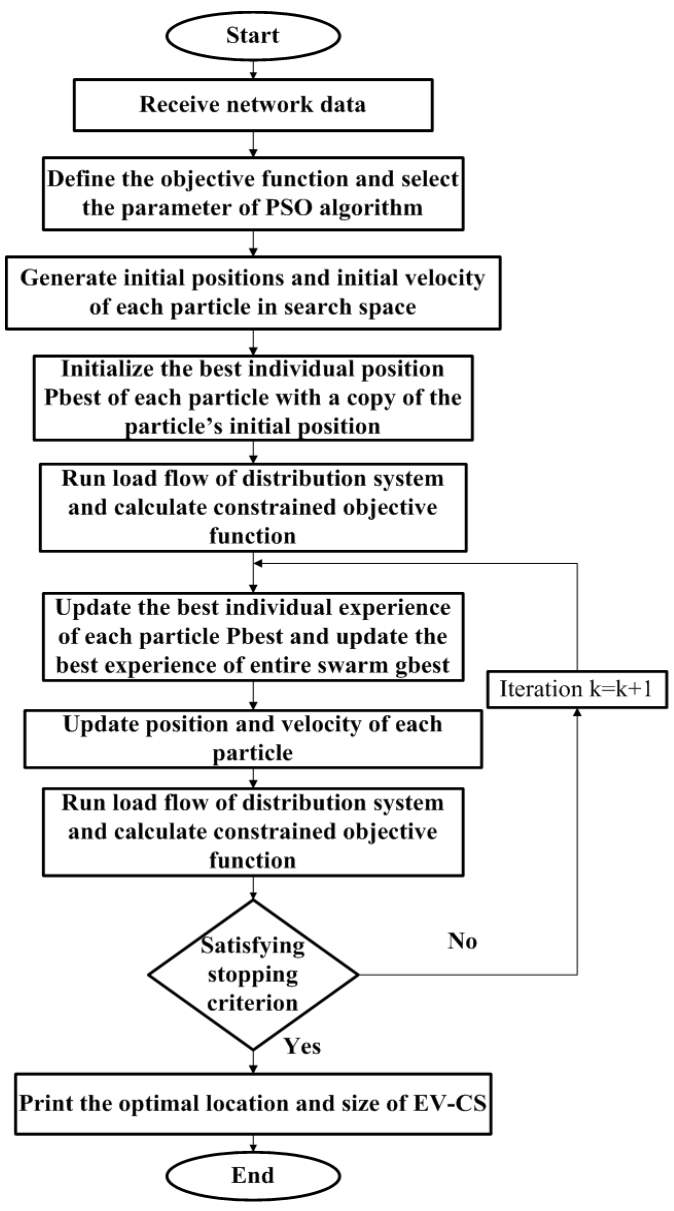

Figure 1. Flowchart of PSO algorithm

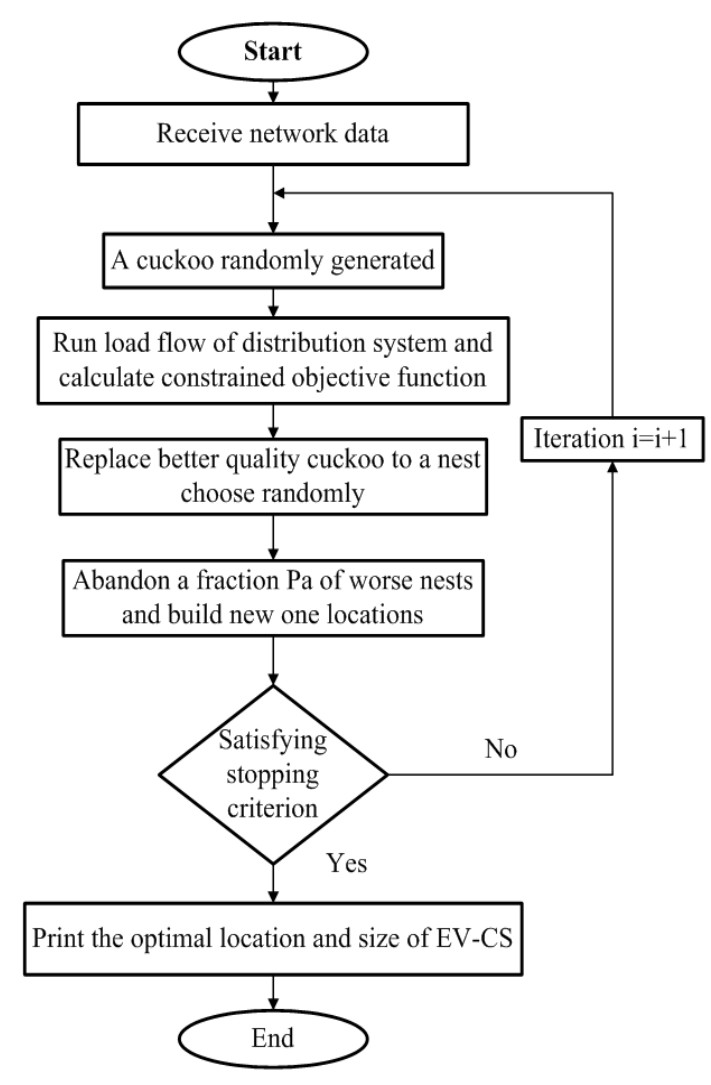

Figure 2. Flowchart of CS algorithm

\subsection{Archimedes optimization algorithm}

AOA is a population-based algorithm. In the suggested solution, the submerged objects are the citizens of the population. AOA also begins the search process with the initial population of objects (candidate solutions) with random volumes, densities and accelerations, as other population-based metaheuristic algorithms. Each object is also initialized at this stage by its random fluid location. AOA functions in iterations after assessing the fitness of the original population before it satisfies the termination criterion. AOA changes the density and volume of every object in every iteration. Object acceleration is modified depending on the state of its collision with some other adjacent object. The updated density, volume, acceleration determines the new position of an object. Following is the detailed mathematical expression of AOA steps [30]. The AOA algorithm is provided in the mathematical formulation. In theory, AOA is a global optimization algorithm, which involves both discovery and operating processes. Algorithm2 presents the pseudo-code of the proposed algorithm; including population initialization, population evaluation, and updating parameters. Mathematically, steps of the proposed AOA are detailed as:

Step 1: initialization, initialize the positions of all objects using (15).

$$
\mathrm{Q}_{\mathrm{i}}=\mathrm{lb}_{\mathrm{i}}+\operatorname{rand} *\left(\mathrm{ub}_{\mathrm{i}}-\mathrm{lb}_{\mathrm{i}}\right) ; \mathrm{i}=1,2,3, \ldots, \mathrm{N}
$$

where $Q_{i}$ is the ith object in a population of $N$ objects.lb $b_{i}$, and $u b_{i}$ are the lower and upper bounds of the search-space, respectively. Initialize volume (vol) and density (den) for each ith object using (16):

$$
\begin{aligned}
& \operatorname{den}_{i}=\text { rand } \\
& \operatorname{vol}_{i}=\text { rand }
\end{aligned}
$$

where rand is a D dimensional vector randomly generates number between $[0,1]$. And finally, initialize acceleration (acc) of ith object using (17):

$$
a c c_{i}=l b_{i}+\operatorname{rand} *\left(u b_{i}-l b_{i}\right)
$$


In this step, evaluate initial population and select the object with the best fitness value. Assign,

$$
x_{\text {best }}, \text { den }_{\text {best }}, \text { vol }_{\text {best }}, \text { andacc }_{\text {best }} .
$$
using (18):

Step 2: update densities, volumes the density and volume of object $i$ for the iteration $t+1$ is updated

$$
\begin{aligned}
\operatorname{den}_{i}^{t+1} & =\operatorname{den}_{i}^{t}+\operatorname{rand} *\left(\text { den }_{\text {best }}-\operatorname{den}_{i}^{t}\right. \\
\operatorname{vol}_{i}^{t+1} & =\operatorname{vol}_{i}^{t}+\operatorname{rand} *\left(\text { vol }_{\text {best }}-\text { vol }_{i}^{t}\right)
\end{aligned}
$$

where $v_{\text {ol }} l_{\text {best }}$ and den $n_{\text {best }}$ are the volume and density associated with the best object found so far, and rand is uniformly distributed random number.

Step 3: transfer operator and density factor in the beginning, collision between objects occurs and after a period of time, the objects try to reach at equilibrium state. This is implemented in AOA with the help of transfer operator $T F$ which transforms search from exploration to exploitation, defined using (19):

$$
T F=\exp \left(\frac{t_{\max }-t}{t_{\max }}\right)
$$

where transfer $T F$ increases gradually with time until reaching 1 . Here $t$ and $t_{\text {max }}$ are iteration number and maximum iterations, respectively. Similarly, density decreasing factor $d$ also assists AOA on global to local search. It decreases with time using (20):

$$
\mathrm{d}^{\mathrm{t}+1}=\exp \left(\frac{\mathrm{t}_{\max }-\mathrm{t}}{\mathrm{t}_{\max }}\right)-\left(\frac{\mathrm{t}}{\mathrm{t}_{\max }}\right)
$$

where $d^{t+1}$ decreases over time and enables convergence in the promising area that has already been established. Note that proper handling of this variable will ensure balance between exploration and exploitation in AOA.

Step 4.1: exploration phase (collision between objects occurs) If $T F \leq 0.5$, collision between objects occurs, select a random material $(\mathrm{mr})$ and update object's acceleration for iteration $t+1$ using $(21)$ :

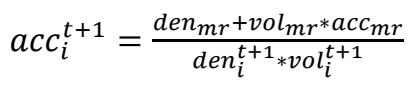

where $d e n_{i}, v l_{i}$, and $a c c_{i}$ are density, volume, and acceleration of object $i$. Where as $a c c_{m r}, d e n_{m r}$ and vol $_{m r}$ are the acceleration, density, and volume of random material. It is important to mention that $T F \leq$ 0.5 ensures exploration during one third of iterations. Applying value other than 0.5 will change explorationexploitation behavior.

Step 4.2: exploitation phase (no collision between objects). IfTF $>0.5$, there is no collision between objects, update object's acceleration for iteration $t+1$ using (22):

$$
\operatorname{acc}_{i}^{t+1}=\frac{\text { den }_{\text {best }}+\text { vol }_{\text {best }} * \text { acc }_{\text {best }}}{\operatorname{den}_{i}^{t+1} * \operatorname{vol}_{i}^{t+1}}
$$

where $a c c_{\text {best }}$ is the acceleration of the best object.

Step 4.3: normalize acceleration, normalize acceleration to calculate the percentage of change using

$$
a c c_{i-n o r m}^{t+1}=u * \frac{a c c_{i}^{t+1}-\min (a c c)}{\max (a c c)-\min (a c c)}+l
$$

where $u$ and $l$ are the range of normalization and set to 0.9 and 0.1 , respectively. The $a c c_{i-n o r m}^{t+1}$ determines the percentage of step that each agent will change. If the object $i$ is far from being globally optimal, the acceleration value would be high - meaning that the object will be in the discovery process; otherwise, it will be in the exploitation phase. This shows how the hunt is shifting from scanning to manipulation. The acceleration factor usually starts with high value and decreases with time. This helps quest engineers travel to 
and from the right global solution They are turning away from local options concurrently. However, it is worth noting that certain search agents may remain that need more time than average to remain in a search point. AOA then hits the balance.

Step 5: update position If $\mathrm{TF} \leq 0.5$ (exploration phase), the $i^{\text {th }}$ object's position for next iteration $t+1$ using (24)

$$
x_{i}^{t+1}=x_{i}^{t}+C_{1} * \text { rand } * a c c_{i-n o r m}^{t+1} * d *\left(x_{\text {rand }}-x_{i}^{t}\right)
$$

where $C_{1}$ is constant equals to 2 . Otherwise, if $T F>0.5$ (exploitation phase), the objects update their positions using (25).

$$
x_{i}^{t+1}=x_{\text {best }}^{t}+F * C_{2} * \text { rand } * \operatorname{acc}_{i-\text { norm }}^{t+1} * d *\left(T * x_{\text {best }}-x_{i}^{t}\right)
$$

where $C_{2}$ is a constant equal to $6 . T$ increases with time and it is directly proportional to transfer operator and it is defined using $T=C_{3} \times T F . T$ increases with time in range $\left[C_{3} * 0.3,1\right]$ and takes a certain percentage from the best position, initially. It begins with a small percentage as these lead to a large gap between the best position and the current position, so the random walk step-size would be high. This proportion increases progressively to reduce the gap between the optimal location and the current position as the hunt progresses. This leads to achieving an appropriate balance between exploration and exploitation. $F$ is the flag to change the direction of motion using (26):

$$
F= \begin{cases}+1 & \text { if } P \leq 0.5 \\ -1 & \text { if } P>0.5\end{cases}
$$

where $P=2 \times$ rand $-C_{4}$.

Step 6: evaluation, evaluate each object using objective function $\mathrm{f}$ and remember the best solution found so far. Assign $x_{\text {best }}$, den $_{\text {best }}, v$ ol $_{\text {best }}$, and $a c c_{\text {best }}$.

\section{OPTIMIZATION TECHNIQUE}

The problem is solved for the base case and then the proposed algorithm is applied to detect the optimal location and size of the EV-CSS. The procedure for solving the problem can be summarized as:

Step 1: enter input data: line data, bus data.

Step 2: run the load flow program, for the base case, to determine the bus voltage profile, branches current, and network power losses.

Step 3: initialization of optimization algorism. Set the iteration counter $\mathrm{k}=0$.

Step 4: run power flow to determine the objective function.

Step 5: compute the CSs size and location according to iterative steps.

Step 6: rebait for $\mathrm{K}=\mathrm{k}+1$ and go to step 4 .

Step 7: comparison between the new power loss and the base case loss. If the difference is less or equal to the tolerance error. Then stop and record the results. Otherwise, go to step 3

\section{CASE STUDY}

\subsection{System data}

The proposed algorithms are used on a 33-bus distribution network with substation voltage of 12.66 $\mathrm{KV}$, base 100 MVA and total load of 3.7 MW and 2.3 MVAR [31]. And it has been implemented using MATLAB environment to run the load flow, calculate power losses, voltage stability index and identify the optimal size and location of EV-CS unit. Figure 3 shows the modified system with different load types connected to each bus.

\subsection{Load modeling and daily load curves}

Loads of the distribution network presents distinct behaviors for variations in grid voltage. For e.g., the voltage magnitude is affected strongly by the real and reactive power usage of fluorescent lamps, whereas personal computers are less susceptible to voltage variations [32]. The actual load of the device does not consist of constant power, constant current or constant form of impedance but is fundamentally complex. Different groups and types of loads could be present in delivery systems, such as residential industrial and commercial loads. In this article, the study takes into account the static load model. Can express the real and 
reactive power static load model in polynomial form. The Polynomial Load Model Characteristic [33] can be given as:

$$
\begin{aligned}
& \boldsymbol{P L}=P L_{0}\left[F_{Z}\left(\frac{V}{V_{0}}\right)^{2}+F_{I}\left(\frac{V}{V_{0}}\right)+F_{P}\right] \\
& \boldsymbol{Q} \boldsymbol{L}=Q L_{0}\left[F^{\prime}{ }_{Z}\left(\frac{V}{V_{0}}\right)^{2}+F_{I}^{\prime}\left(\frac{V}{V_{0}}\right)+F_{P}^{\prime}\right]
\end{aligned}
$$

where constants $F$ and $F^{\prime}$ are fractions; and the subscripts $Z$, $I$ and $P$ stand for constant impedance, constant current, and constant power contributions, respectively. $F_{Z}+F_{I}+F_{P}=1$ and $F_{Z}^{\prime}+F_{I}^{\prime}+F_{P}^{\prime}=1$. The values of the real and reactive constants used in the present work for industrial, residential, and commercial loads are given in Table 1 [34]. A typical daily load curves of industrial, residential, and commercial load types are given in Figures 4, 5and 6 respectively [35].

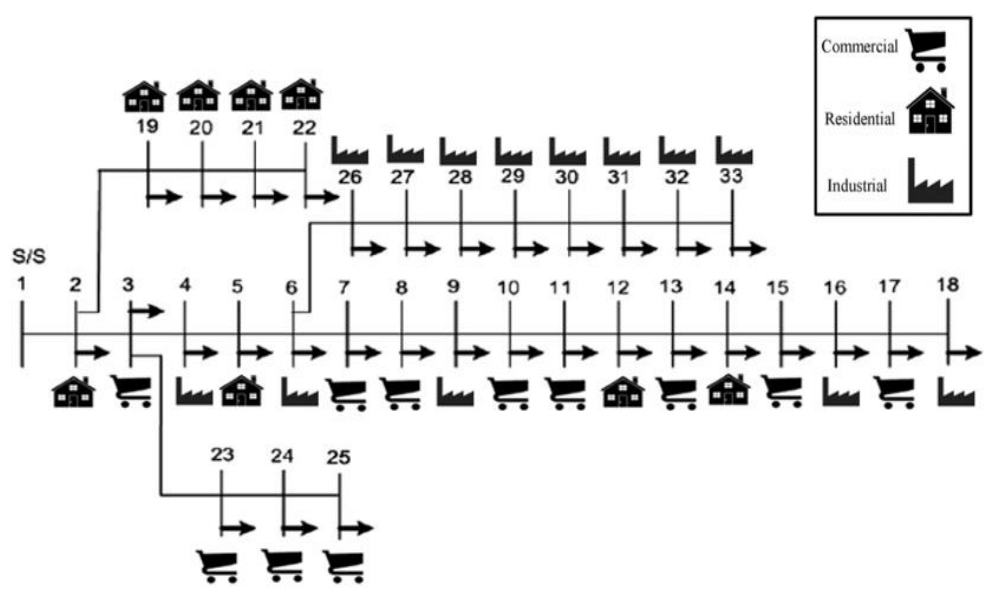

Figure 3. The modified 33 bus radial distribution networks

Table 1. The composition values of different loads

\begin{tabular}{clccc}
\hline & Composition & $F_{Z}$ & $F_{I}$ & $F_{P}$ \\
\hline \multirow{4}{*}{ Active Power } & Residential & 0.24 & 0.62 & 0.13 \\
& Commercial & 0.16 & 0.80 & 0.04 \\
& Industrial & -0.07 & 0.24 & 0.83 \\
& Residential & 2.44 & -1.94 & 0.50 \\
Reactive Power & Commercial & 3.26 & -3.10 & 0.84 \\
& Industrial & 1.00 & 0.00 & 0.00 \\
\hline
\end{tabular}

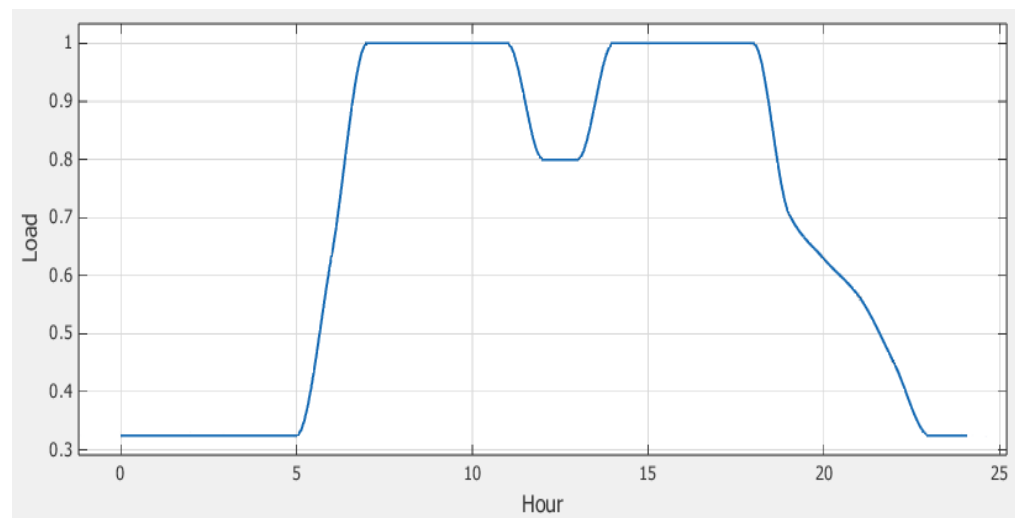

Figure 4. Industrial load curve 


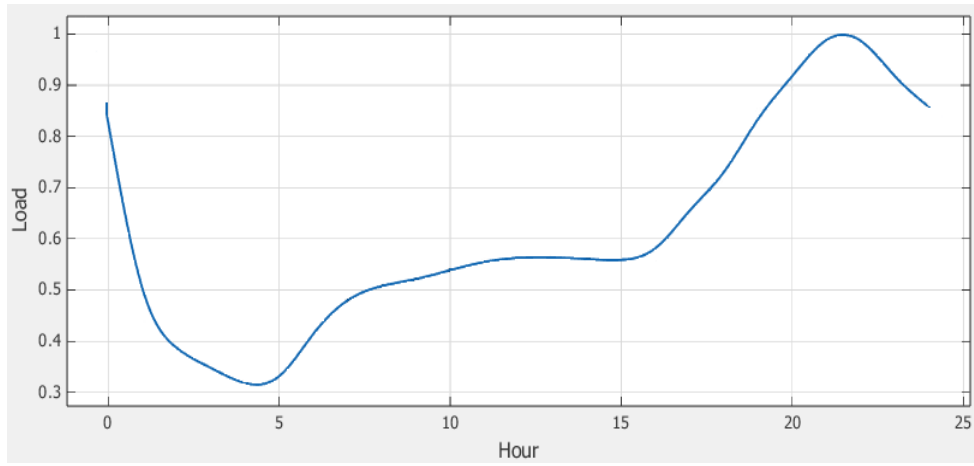

Figure 5. Residential load curve

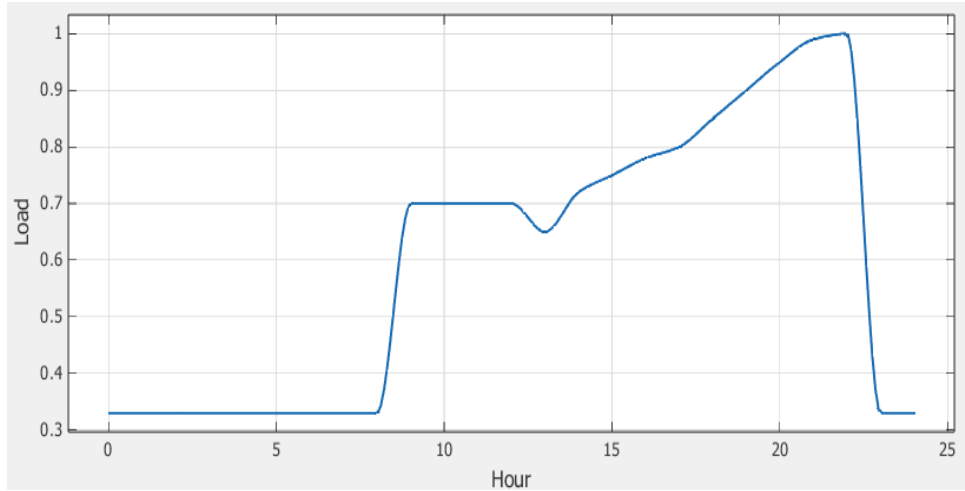

Figure 6. Commercial load curve

\subsection{Data of PV system}

The following data of PV system in Table 2. Itis including the type of PV modules, the power, size of modules. The cost from ENFSOLAR website (cost taken at 5/2/2021) [36].

Table 2. Type of PV modules, price of items and the size of PV module

\begin{tabular}{|c|c|c|c|c|c|c|c|c|c|c|c|c|}
\hline Type & $\begin{array}{l}\text { Power } \\
\text { (w) }\end{array}$ & At Irr. & $\begin{array}{l}\text { Length } \\
(\mathrm{mm})\end{array}$ & $\begin{array}{l}\text { Width } \\
(\mathrm{mm})\end{array}$ & $\begin{array}{l}\text { Area } \\
\left(\mathrm{m}^{2}\right)\end{array}$ & $\begin{array}{l}\text { Power } \\
(\mathrm{MW})\end{array}$ & $\begin{array}{c}\text { No. of } \\
\text { Modules }\end{array}$ & $\begin{array}{c}\text { Price } \\
\text { L.E/ item) }\end{array}$ & $\begin{array}{c}\text { LE } \\
\text { (million) }\end{array}$ & $\begin{array}{l}\text { Area } \\
\left(\mathrm{m}^{2}\right)\end{array}$ & $\begin{array}{c}\text { Length } \\
(\mathrm{mm})\end{array}$ & $\begin{array}{l}\text { Width } \\
(\mathrm{mm})\end{array}$ \\
\hline $\begin{array}{l}\text { Trina Solar } \\
\text { TSM-PE15H }\end{array}$ & 340 & at $1000 \mathrm{~W} / \mathrm{m} 2$ & 2024 & 959 & 1.941016 & 2.5 & 7353 & 1632 & 12 & 14272 & 150 & 95 \\
\hline $\begin{array}{l}\text { Poly-325W, } \\
\text { Polycrystalline }\end{array}$ & 325 & at $1000 \mathrm{~W} / \mathrm{m} 2$ & 1956 & 992 & 1.940352 & 2.5 & 7692 & 890.5 & 6.850 & 14936 & 150 & 100 \\
\hline $\begin{array}{l}\text { Series: GPNE- } \\
\text { S144/FNH 435- } \\
\text { 460W, } \\
\text { Monocrystalline }\end{array}$ & 460 & at $1000 \mathrm{~W} / \mathrm{m} 2$ & 2108 & 1048 & 2.209184 & 2.5 & 5435 & 1591.5 & 8.6495 & 2006 & 150 & 80 \\
\hline
\end{tabular}

\section{RESULTS AND DISCUSSION}

According to load modelling and different load curves mentioned, Figure 7 shows the daily load profile of the substation (at bus\#1). It can be observed from that the daily load is continuously varying and the peak load is $3.255 \mathrm{MW}$ at hour 18 (6 PM). Table 3 and Figure 8 shows the best location and size for 24 hours of the three optimization techniques. Table 3 shows the effects of various load types include the effect of load variations throughout a day in the optimal location and size of EV-CS. It can be seen from Table 3 that the results obtained by the proposed algorithms are concur with each other and that is show the validity of the results. From Table 3, it can be highlighted that the maximum size of EV-CS unit is $2.27 \mathrm{MW}$ at peak load hour of day so the design of PV size must be around this size and located at bus 6 . 


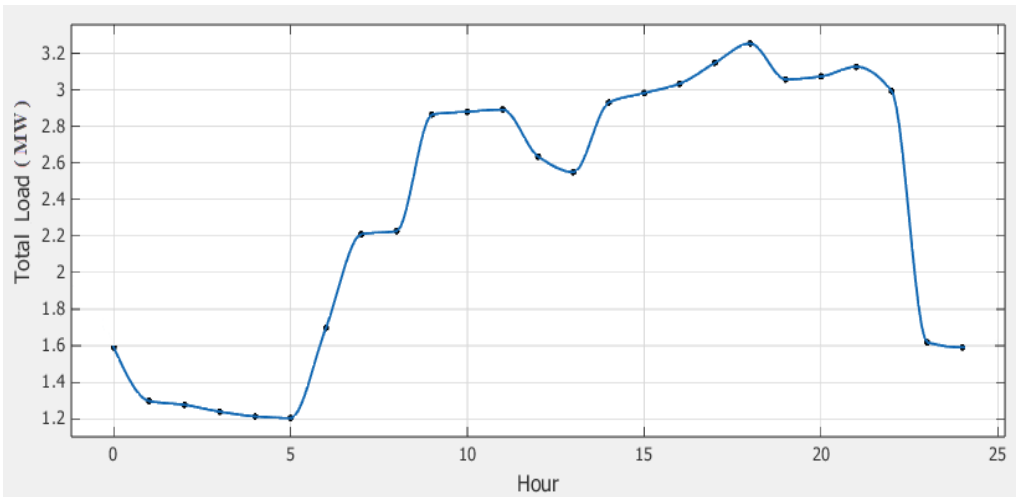

Figure 7. Daily load profile of the substation

Table 3. EV-CS size and location by the proposed algorithms for all hours of a day

\begin{tabular}{|c|c|c|c|c|c|c|c|c|c|c|c|c|c|}
\hline \multirow[t]{3}{*}{ Hour } & \multicolumn{2}{|c|}{ PSO } & \multicolumn{2}{|c|}{$\mathrm{CS}$} & \multicolumn{2}{|c|}{$\mathrm{AOA}$} & \multirow[t]{3}{*}{ Hour } & \multicolumn{2}{|c|}{ PSO } & \multicolumn{2}{|c|}{$\mathrm{CS}$} & \multicolumn{2}{|c|}{$\mathrm{AOA}$} \\
\hline & Bus & Size & Bus & Size & Bus & Size & & Bus & Size & Bus & Size & Bus & Size \\
\hline & No. & MW & No. & MW & No. & MW & & No. & MW & No. & MW & No. & MW \\
\hline 1 & 6 & 0.8353 & 6 & 0.8482 & 6 & 0.8123 & 13 & 6 & 1.76 & 6 & 1.6966 & 6 & 1.6998 \\
\hline 2 & 6 & 0.7668 & 6 & 0.7895 & 6 & 0.8056 & 14 & 6 & 2.0084 & 6 & 2.0189 & 6 & 1.9973 \\
\hline 3 & 6 & 0.7180 & 6 & 0.7910 & 6 & 0.7936 & 15 & 6 & 1.9954 & 6 & 2.0135 & 6 & 2.0242 \\
\hline 4 & 6 & 0.7717 & 6 & 0.7836 & 6 & 0.7852 & 16 & 6 & 2.1331 & 6 & 2.0864 & 6 & 2.0511 \\
\hline 5 & 6 & 0.8549 & 6 & 0.7702 & 6 & 0.7823 & 17 & 6 & 2.1074 & 6 & 2.0995 & 6 & 2.0938 \\
\hline 6 & 29 & 0.8281 & 29 & 0.8128 & 29 & 1.184 & 18 & 6 & 2.2752 & 6 & 2.1525 & 6 & 2.1451 \\
\hline 7 & 30 & 1.0595 & 30 & 1.0919 & 30 & 1.6283 & 19 & 6 & 1.7487 & 6 & 1.8503 & 6 & 1.8804 \\
\hline 8 & 30 & 1.0140 & 30 & 1.0923 & 30 & 1.6336 & 20 & 7 & 1.7906 & 7 & 1.7595 & 7 & 1.8448 \\
\hline 9 & 6 & 1.9326 & 6 & 1.9358 & 6 & 1.9696 & 21 & 7 & 1.7926 & 7 & 1.7446 & 7 & 1.827 \\
\hline 10 & 6 & 2.0849 & 6 & 1.9379 & 6 & 1.9741 & 22 & 7 & 1.5943 & 7 & 1.6305 & 7 & 1.7017 \\
\hline 11 & 6 & 1.9918 & 6 & 1.9591 & 6 & 1.9778 & 23 & 6 & 0.9442 & 6 & 0.913 & 6 & 0.9156 \\
\hline 12 & 6 & 1.8291 & 6 & 1.7282 & 6 & 1.7451 & 24 & 7 & 0.7031 & 7 & 0.8808 & 7 & 0.9068 \\
\hline
\end{tabular}

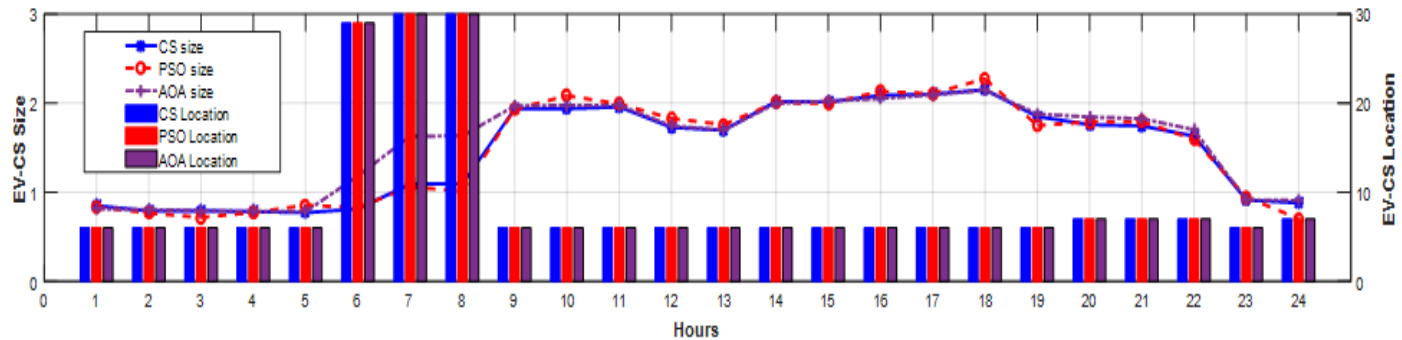

Figure 8. EV-CS allocation by using AI technique

Table 4 and Figure 9, shows total power and power loss by the proposed algorithms for all hours of a day, it can be highlighted that the total power 3.25 MW, and maximum power loss $77.47 \mathrm{kw}$ at peak load hour of day. From the Table 3, it can see that the total power losses for the system at worst hour (18:00) are improved than the base case (power losses improved from $142.509 \mathrm{kw}$ to $77.47 \mathrm{kw}, 45.64 \%$ reduction). It can also see that AOA has best result than CS and PSO. Taking hour 18 as an example the power losses is $77.2475 \mathrm{kw}$ in case of AOA technique better than that of PSO which is $77.4738 \mathrm{kw}$ and CS which is $77.2482 \mathrm{kw}$.

Figure10 shows the voltage profile for all busses in the system at worst hour (18:00). From the Figure 10 it can be seen that the voltage profile is improved than the base case (minimum voltage at bus 33 improved from $0.9279 \mathrm{pu}$ to $0.9579 \mathrm{pu}$ ). It can also see that AOA has best result than CS and PSO. Taking bus 33 as an example the voltage magnitued is 0.9579 p.u. in case of AOA technique better than that of PSO which is 0.9562 p.u. and CS which is 0.9563 p.u. Table 4 shown the number of modules for the type in, the price of items and the size of module. 
Table 4. Total power and power loss by the proposed algorithms for all hours of a day

\begin{tabular}{|c|c|c|c|c|c|c|c|c|c|c|c|}
\hline Hour & $\begin{array}{l}P_{\text {total }} \\
\mathrm{MW}\end{array}$ & $\begin{array}{l}\text { Base } \\
\text { Case } \\
\mathrm{P}_{\text {loss }} \\
\mathrm{KW}\end{array}$ & $\begin{array}{l}\text { PSO } \\
\mathrm{P}_{\text {loss }} \\
\mathrm{KW}\end{array}$ & $\begin{array}{l}\text { CS } \\
\mathrm{P}_{\text {loss }} \\
\mathrm{KW}\end{array}$ & $\begin{array}{c}\text { AOA } \\
\mathrm{P}_{\text {loss }} \\
\mathrm{KW}\end{array}$ & Hour & $\mathrm{P}_{\text {total }}$ & $\begin{array}{l}\text { Base } \\
\text { Case } \\
\mathrm{P}_{\text {loss }} \\
\mathrm{KW}\end{array}$ & $\begin{array}{l}\text { PSO } \\
\mathrm{P}_{\text {loss }} \\
\mathrm{KW}\end{array}$ & $\begin{array}{l}\mathrm{CS} \\
\mathrm{P}_{\text {loss }} \\
\mathrm{KW}\end{array}$ & $\begin{array}{c}\text { AOA } \\
\mathrm{P}_{\text {loss }} \\
\mathrm{KW}\end{array}$ \\
\hline 2 & 1.2761 & 19.4066 & 10.5462 & 10.5295 & 10.5261 & 14 & 2.9317 & 125.5539 & 69.2177 & 69.2223 & 69.2161 \\
\hline 3 & 1.239 & 18.8198 & 10.2803 & 10.2038 & 10.2038 & 15 & 2.9829 & 128.4732 & 70.5712 & 70.5616 & 70.5602 \\
\hline 4 & 1.2131 & 18.4212 & 9.9898 & 9.9874 & 9.9874 & 16 & 3.034 & 131.4447 & 72.0238 & 71.9506 & 71.934 \\
\hline 7 & 2.2108 & 90.6903 & 50.4582 & 50.4215 & 53.6328 & 19 & 3.0578 & 105.8258 & 56.267 & 56.0462 & 56.0342 \\
\hline 8 & 2.2276 & 91.1845 & 50.9631 & 50.7518 & 53.8834 & 20 & 3.0737 & 101.1529 & 53.275 & 53.2625 & 53.2673 \\
\hline 9 & 2.8661 & 122.5165 & 67.7903 & 67.7872 & 67.772 & 21 & 3.1268 & 99.0073 & 51.9046 & 51.8755 & 52.061 \\
\hline 10 & 2.8808 & 123.0376 & 68.1982 & 68.0518 & 68.0343 & 22 & 2.9932 & 85.8367 & 44.8959 & 44.8739 & 45.2461 \\
\hline 11 & 2.8927 & 123.4615 & 68.2507 & 68.2527 & 68.2481 & 23 & 1.6184 & 25.6899 & 14.1992 & 14.1883 & 14.1883 \\
\hline 12 & 2.6356 & 93.5427 & 50.919 & 50.8286 & 50.8248 & 24 & 1.5911 & 25.1315 & 14.1411 & 13.8697 & 13.851 \\
\hline
\end{tabular}

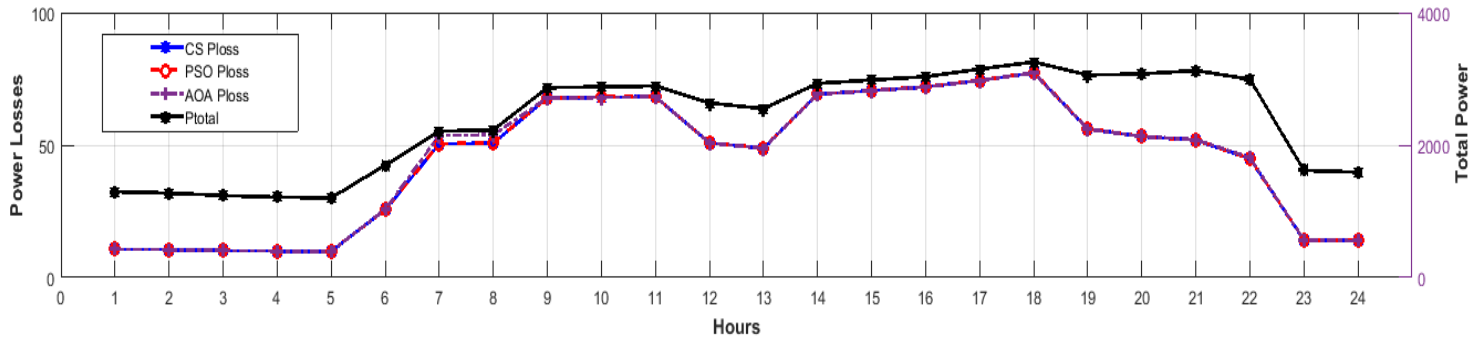

Figure 9. Total power and power losses by using AI technique

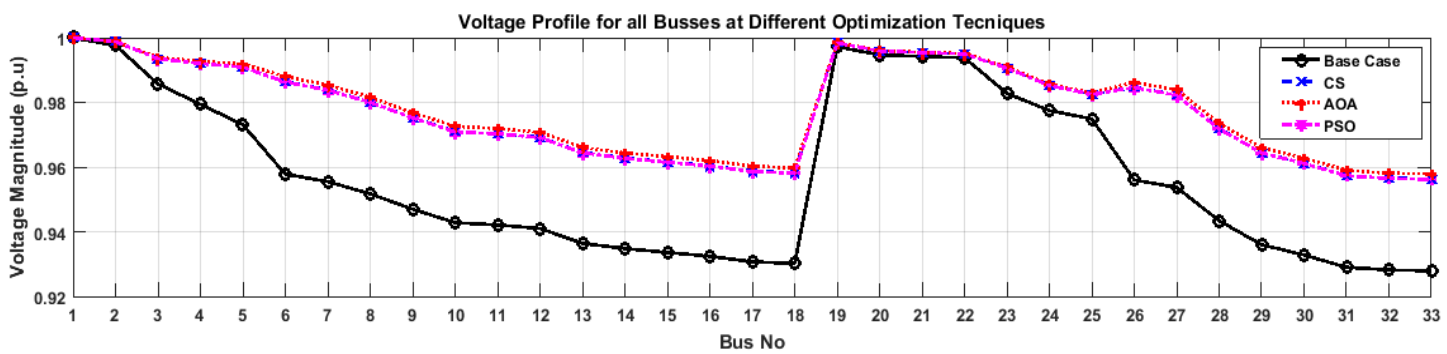

Figure 10. Voltage profile

\section{CONCLUSION}

This paper conducts a comprehensive research and analysis on EV-CS optimal allocation-CS comprehensive optimization model with minimum power loss as the objective is proposed, and a method for solving the model is presented based on AOA. The paper handles EV-CS locations and capacities for optimal configuration. The optimal configuration schemes ensure the system operates in an optimal state in the sense of power loss. Comparing the results of AOA with CS and PSO in this paper, AOA has faster convergence speed, shorter running time and more stable results in dealing with configuration problems. The results show that the AOA has obvious advantages in solving the EV-CS configuration problem. In future work, we used the multi objectives to determine the optimal allocation of EVCS such as minimization of cost, and power loss study the effective of EV on the grid (V2G and G2V) and implementation to an actual distribution network in Egypt.

\section{REFERENCES}

[1] F. Fazelpour, M. Vafaeipour, O. Rahbari, and M. A. Rosen, "Intelligent optimization to integrate a plug-in hybrid electric vehicle smart parking lot with renewable energy resources and enhance grid characteristics," Energy Conversion and Management, vol. 77, pp. 250-261, January 2014, doi: 10.1016/j.enconman.2013.09.006.

[2] U.S. Energy Information Administration (EIA), “Annual EnergyOutlook 2011," U.S. Department of energy, Washington DC, 2011. 
[3] M. H. Amini, K. G. Boroojeni, Cheng Jian Wang, A. Nejadpak, S. S. Iyengar, and O. Karabasoglu, "Effect of electric vehicle parking lots' charging demand as dispatchable loads on power systems loss,"2016 IEEE International Conference on Electro Information Technology (EIT), 2016, pp. 0499-0503, doi: 10.1109/EIT.2016.7535291.

[4] J. Garcia-Guarin, W. Infante, Ma, D. Alvarez, and S. Rivera, "Optimal scheduling of smart microgrids considering electric vehicle battery swapping stations," International Journal of Electrical and Computer Engineering (IJECE), vol. 10, no. 5, October 2020, pp. 5093-5107, doi: 10.11591/ijece.v10i5.pp5093-5107.

[5] A. Geetha and C. Subramani, "A significant energy management control strategy for a hybrid source EV," International Journal of Electrical and Computer Engineering (IJECE), vol. 9, no. 6, December 2019, pp. 45804585, doi: 10.11591/ijece.v9i6.pp4580-4585

[6] W. Kempton, and A. Dhanju, "Electric Vehicles with V2G: Storage for Large-Scale Wind Power," Windtech International, vol. 18, no. 2, 2006.

[7] W. Kempton and J. Tomic, "Vehicle-to-grid power fundamentals: Calculating capacity and net revenue," Journal of Power Sources, vol. 144, no. 1, pp. 268-279, 2005, doi: 10.1016/j.jpowsour.2004.12.025.

[8] M. H. Amini, O. Karabasoglu, M. D. Ilić, K. G. Boroojeni and S. S. Iyengar, "ARIMA-based demand forecasting method considering probabilistic model of electric vehicles' parking lots,"2015 IEEE Power \& Energy Society General Meeting, 2015, pp. 1-5, doi: 10.1109/PESGM.2015.7286050.

[9] J. de Hoog et al., "The importance of spatial distribution when analysing the impact of electric vehicles on voltage stability in distribution networks," Energy system, vol. 6, no. 1, pp. 63-84, 2014, doi: 10.1007/s12667-014-0122-8

[10] M. Ehsani, M. Falahi and S. Lotfifard, "Vehicle to grid services: potential and applications," Energies, vol. 5, no. 10, pp. 4076-4090, 2012, doi: 10.3390/en5104076.

[11] M. Honarmand, A. Zakariazadeh, and S. Jadid, "Self-scheduling of electric vehicles in an intelligent parking lot using stochastic optimization," Journal of The Franklin Institute, vol. 352, no. 2, pp. 449-467, 2015, 10.1016/j.jfranklin.2014.01.019.

[12] Z. Liu, F. Wen and G. Ledwich, "Optimal Planning of Electric-Vehicle Charging Stations in Distribution Systems," in IEEE Transactions on Power Delivery, vol. 28, no. 1, pp. 102-110, Jan. 2013, doi: 10.1109/TPWRD.2012.2223489.

[13] A. T. Davda, B. Azzopardi, B. R. Parekh and M. D. Desai, "Dispersed Generation Enable Loss Reduction and Voltage Profile Improvement in Distribution Network - Case Study, Gujarat, India," in IEEE Transactions on Power Systems, vol. 29, no. 3, pp. 1242-1249, May 2014, doi: 10.1109/TPWRS.2013.2292117.

[14] M. H. Moradi, M. Abedini, S. M. R. Tousi, and S. M. Hosseinian, "Optimal sitting and sizing of renewable energy sources and charging stations simultaneously based on differential evolution algorithm," International Journal of Electrical Power and Energy Systems, vol. 73, pp. 1015-1024, December 2015, doi: 10.1016/j.ijepes.2015.06.029.

[15] Y. Li, H. Zhu, D. Wang, K. Wang, W. Kong, and X. Wu, "Comprehensive optimization of distributed generation considering network reconstruction based on Archimedes optimization algorithm," IOP Conf. Series: Earth and Environmental Science, vol. 647, pp. 1-9, 2021, doi: doi:10.1088/1755-1315/647/1/012031.

[16] Z. M. Ali, I. M. Diaaeldin, A. El-Rafei, H. M. Hasanien, S. H.E. A. Aleem, and A. Y. Abdelaziz, "A novel distributed generation planning algorithm via graphically-based network reconfiguration and soft open points placement using Archimedes optimization algorithm," Ain Shams Engineering Journal, vol. 12, no 2, pp. 19231941, June 2021, doi: 10.1016/j.asej.2020.12.006.

[17] G. R. C. Mouli, P. Bauer, and M. Zeman, "Comparison of system architecture and converter topology for a solar powered electric vehicle charging station,"2015 9th International Conference on Power Electronics and ECCE Asia (ICPE-ECCE Asia), 2015, pp. 1908-1915, doi: 10.1109/ICPE.2015.7168039.

[18] P. Goli, and W. Shireen, "PV powered smart charging station for PHEVs," Renewable Energy, vol. 66, pp. 280287, 2014, doi: 10.1016/j.renene.2013.11.066

[19] G. Gamboa et al., "Control strategy of a multi-port, grid connected, direct-DC PV charging station for plug-in electric vehicles,"2010 IEEE Energy Conversion Congress and Exposition, 2010, pp. 1173-1177, doi: 10.1109/ECCE.2010.5617838.

[20] F. Fattori, N. Anglani, and G. Muliere, "Combining photovoltaic energy with electric vehicles, smart charging, and vehicle-to-grid,” Solar Energy, vol. 110, pp. 438-451, 2014, doi: 10.1016/j.solener.2014.09.034.

[21] O. Hafez, and K. Bhattacharya, "Optimal design of electric vehicle charging stations considering various energy resources," Renewable Energy, vol. 107, pp. 576-589, 2017, doi: 10.1016/j.renene.2017.01.066.

[22] G. C. Mouli, P. Bauer, and M. Zeman, "System design for a solar-powered electric vehicle charging station for workplaces," Applied Energy, vol. 168, pp. 434-443, 2016, doi: 10.1016/j.apenergy.2016.01.110.

[23] W. Khan, F. Ahmad, and M. S. Alam, "Fast EV charging station integration with grid ensuring optimal and quality power exchange," Engineering Science and Technology, vol. 22, no. 1, pp. 143-152, 2019, doi: 10.1016/j.jestch.2018.08.005.

[24] J. A. Domínguez-Navarro, R. Dufo-López, J. M. Yusta-Loyo, J. S. Artal-Sevil, and J. L. Bernal-Agustín, "Design of an electric vehicle fast-charging station with integration of renewable energy and storage systems, "International Journal of Electrical Power \& Energy Systems, vol. 105, pp. 46-58, 2019, doi: 10.1016/j.ijepes.2018.08.001.

[25] M. Rupa, and S. Ganesh, "Power flow analysis for radial distribution system using backward/forward sweep method," International Journal of Electrical, Computer, Electronics and Communication Engineering, vol. 8, no. 10, pp. 1540-1544, 2014.

[26] J. Kennedy, and R. Eberhart, "Particle swarm optimization," Proceedings of ICNN'95 - International Conference on Neural Networks, 1995, pp. 1942-1948 vol.4, doi: 10.1109/ICNN.1995.488968. 
[27] M. E. Baran, and F. F. Wu, "Network reconfiguration in distribution systems for loss reduction and load balancing," in IEEE Transactions on Power Delivery, vol. 4, no. 2, pp. 1401-1407, April 1989, doi: $10.1109 / 61.25627$.

[28] X. Yang, and Suash Deb, "Cuckoo Search via Lévy flights,"2009 World Congress on Nature \& Biologically Inspired Computing (NaBIC), 2009, pp. 210-214, doi: 10.1109/NABIC.2009.5393690.

[29] B. Pati and S. B. Karajgi, "Optimized placement of multiple FACTS devices using PSO and CSA algorithms", International Journal of Electrical and Computer Engineering (IJECE), vol. 10, no. 4, August 2020, pp. 33503357, doi: 10.11591/ijece.v10i4.pp3350-3357.

[30] F. A. Hashim, K. Hussain, E. H. Houssein, M. S. Mabrouk, and W. Al-Atabany, "Archimedes optimization algorithm: a new metaheuristic algorithm for solving optimization problems," Applied Intelligence, vol. 51, pp. 1531-1551, 2021, doi: 10.1007/s10489-020-01893-z.

[31] M. E. Baran, and F. F. Wu, "Network reconfiguration in distribution systems for loss reduction and load balancing," in IEEE Transactions on Power Delivery, vol. 4, no. 2, pp. 1401-1407, April 1989, doi: $10.1109 / 61.25627$.

[32] L. M. Vargas Rios, "Local Voltage Stability Assessment for Variable Load Characteristic" M. S. thesis, Faculty Electrical and Computer Engineering, Univ. British Columbia, Vancouver, BC, Canada, 2009. [Online]. Available: https://circle.ubc.ca/handle/2429/21424

[33] T. V. Cutsem and C. Vournas, Voltage Stability of Electric Power Systems. New York: Springer, 1998.

[34] W. W. Price, K. A. Wirgau, A. Murdoch, J. V. Mitsche, E. Vaahedi and M. El-Kady, "Load modeling for power flow and transient stability computer studies," in IEEE Transactions on Power Systems, vol. 3, no. 1, pp. 180-187, Feb. 1988, doi: 10.1109/59.43196.

[35] B.R. Gupta, "Generation of Electrical Energy", 3rd edition, Eurasia Publishing House (PVT.) Ltd Ram Nagar, New Delhi, 1996.

[36] ENF Solar, Solar Panel Directory, [Online]. Available: https://www.enfsolar.com/pv/panel?gclid=EAIaIQobChMI3vj0dXN7gIV1OvtCh3H6wPEEAAYAiAAEgI39PD_Bw E. Date of accesse $5 / 2 / 2021$ 